\title{
An Introduction to the Special Issue on "Behavioural Economics, Consumer Policy, and Consumer Law"
}

\author{
Hans-W. Micklitz • Lucia A. Reisch • Kornelia Hagen • \\ on behalf of the JCP Editors
}

Published online: 29 June 2011

(C) Springer Science+Business Media, LLC. 2011

European consumer policy-coupled with the European Economic Constitution and European consumer law - is based on an assumption of rational-acting consumers and suppliers and is deeply rooted in the information paradigm. The information paradigm indicates that asymmetric information can be an impediment to welfare-enhancing consumer decision making. To improve the position of the consumer in markets, regulated information on products and services as well as on rights and remedies are seen as the key devices of consumer policy. The information paradigm suggests that there are consumers who are able, willing, and competent to deal with information provided, to read different languages, to take informed rational decisions and to enforce their information-based rights. Consumers are mostly regarded as individuals. The collective dimension of consumer law and consumer policy is largely set aside.

The philosophy behind this is that of Hammurabi, i.e., it suffices to write down the law and to make sure that the consumer knows the law in order to guarantee that one's rights are taken seriously. However, as the recent "Consumer Market Scoreboard" (European Union 2011) has shown, while about three quarters of the respondents believe that consumer organizations are protecting their rights, only $13 \%$ of consumers say that they actually make use of their consumer rights on the individual level. Of those, only about half are satisfied with the results of their complaints. As the scoreboard rightly states (ibid), poor complaint handling by companies is both a source of harm to consumers and a missed opportunity to reinforce consumer loyalty.

The current information paradigm is a normative paradigm. It builds on a specific assumption of human behaviour and on a legal system which is designed to enforce this

\section{H.-W. Micklitz}

European University Institute, Florence, Italy

\author{
L. A. Reisch $(\bowtie)$ \\ Copenhagen Business School, Copenhagen, Denmark \\ e-mail: 1r.ikl@cbs.dk
}

K. Hagen

German Institute for Economic Research, Berlin, Germany 
normative concept. More legally speaking, the information paradigm creates obligations upon suppliers to provide relevant information. Nowadays, the consumer legal system is saturated with information duties, duties that tend to produce high costs for suppliers and also inundate the legal system. The result is an ever-growing enforcement deficit. The supplier faces difficulties in providing all the relevant information and there is significant debate regarding the value of this information provision, particularly concerning the extent to which it actually enhances the consumer decision-making process.

In response to some of the limitations of the rational information processing paradigm, there is a growing academic and policy interest in behavioural economics (BE) as an alternative or in some ways complimentary approach to improving the consumer position in the marketplace. BE looks into the empirics of the market and analyses how market participants actually behave, how they deal with the information they receive, what their limitations are as regards cognitive ability to solve optimization problems, and to enforce their rights. Moreover, BE systematically investigates consumers' heuristics and biases along with our limitations in decision making. It also investigates the power of defaults and the influence of the environment.

Driven by the discussion around "Nudge" (Thaler and Sunstein 2008), politicians around the globe are looking into "choice architecture" and default settings surrounding personal decisions that might cause consumers to choose differently and better. To dig deeper into the recently launched discussion on the implications of BE for consumer policy and law in general and the information paradigm specifically, the Journal of Consumer Policy invited a group of 30 leading academics representing a broad range of social sciences as well as consumer policy makers to a 2-day symposium on "Behavioural Economics, Consumer Policy, and Consumer Law" which was held on the premises of the European University Institute in Florence in June 2010. The symposium covered a broad range of issues grouped around three themes: Behavioural economics and the law (1); information, consumer decision making, and behaviour (2); rational politics for irrational consumers (3). Most of the papers in this special issue were presented at this symposium and have benefitted from the discussions that took place there.

The first paper, written by Amitai Etzioni, provides for a review on the methodology and the limitations of behavioural economics which require some "new steps." Although the paper does not address consumer policy explicitly, his explanations are nonetheless applicable to consumer policy. He highlights as achievements the successful replication of key findings; not at all an often met criterion in social science research, such as anchoring and adjustment (Jacowitz and Kahneman 1995) and the endowment effect (Ariely 2008; Loewenstein 2004). Empirics of behavioural economics are no longer only results of experiments under lab conditions but rely nowadays also on field data. The third achievement of behavioural economics is the transparency of the methodology. In contrast to behavioural economics, some other disciplines make extensive use of regression analysis, weighting and do not spell out their analysis assumptions. As opposed to neoclassical research, BE avoids tautological reasoning.

The second part of the paper deals with critical interpretations and characteristics of behavioural economics. He refers to differences with regard to the extent to which people fail to optimize their utility/choices, thereby differentiating universalistic (bias strike all people, quasi inherent), particularistic (the choices of only some people are biased) or oscillation (the same person sometimes is biased, sometimes not) limitations. He suggests that behavioural economics should clarify the extent to which people fail to optimize. The author's concern is that behavioural economics treats rationality as a dichotomous variable (possibly only optimizing or not optimizing) instead of a continuous variable. He mentions 
the concept of degrees of rationality of Costa-Gomes et al. (2001) which considers the impact of socio-economic factors such as education, self-control, values et cetera, on decision making. The author refers again to Thaler and Sunstein (2008) and their liberal choice architecture which entails arrangements that should help people to make better choices, for example by learning to control loss aversion, handling of information, or using defaults.

Lastly, the author looks into affective, normative, and macro variables. Behavioural economics is said to indicate the inability to optimize rational economic decisions as a result of cognitive limitations and emotions such as loss aversion, as well as normative factors such as social norms (trust, fairness, group, or individual decision-making processes). According to him the impact of these variables must be studied separately. However, most behavioural economics studies do not deal with interpersonal relations, and do not look at the social context of individuals (exceptions can be found in the work of Camerer (2003) and Sobel (2006) for instance). The author advocates for the need to observe the role of culture needs and culture impact. He motivates behavioural economists to combine group experiments with personal ones so as to investigate the desire to conform to social norms. "The more behavioural economics explores the affective and normative factors that influences choices," the more it will be established that the "neo-Romantic" model is more realistic.

In the conclusion, Etzioni poses the question whether "behavioural economics seeks to augment, modify, deeply alter, or replace the basic neoclassical economic paradigm and its implications for choice behaviour." He advocates for another paradigm on the micro-level as well as on the macro-level. There is "no principled reason behavioural economics should shy away from engaging in a competition between its paradigm and the neoclassical one."

Sabine Frerichs paper also reaches far beyond consumer law and consumer policy, although its findings are of high relevance for the future design of consumer law and consumer policy. It deals with the century-long attempts of the law to integrate the findings of social science and later economics into its inner system. Her paper must be put into line with similar attempts in the American legal doctrine (Nourse and Shaffer 2009). The "law and disciplines" (law and sociology, law and political sciences, law and psychology, law and economics, law and behavioural economics) document the irritation and the difficulty of the "law" to find its place in between the two significant branches of social science and economics.

For Frerichs, Freakonomics and Nudge constitute a source of inspiration also for lawyers. These latter two books have already become an important reference in the field of consumer law and policy. In principle, her argument is that there is nothing to complain about law's encounter with science, namely the social sciences. Notably, the law and economics movement proved successful in importing economic perspectives into legal discourse. However, she questions if the law should follow each trend on the academic book market. She draws a parallel between an increasing emphasis on economic perspectives at the expense of sociological perspectives within the field of law, economy, and society, and more significantly in the field of law and economics. Her major argument is that with the behavioural turn in law and economics, homo oeconomicus seems to have been transformed into Homer Economicus, and consumer law has become prone to the Simpsonized process, a paradigm shift which constitutes a challenge for consumer law and policy.

The shift from neoclassical law and economics to behavioural law and economics is analysed from a sociological perspective: the economic sociology of law. In this framework, the author compares and confronts the "old" homo oeconomicus rationalis and the "new" 
homo oeconomicus behavioralis with a third model—homo economicus culturalis - which demonstrates the limits of the previous models, not least with regard to explaining the recent financial crisis. While governance by nudges might appear, at first sight, as a tempting idea, Frerichs questions the normative side of this project and emphasize its possible effects on our legal culture and, thereby, our human condition. She concludes: "The projected task of the economic sociology of law is, notably, to put the ongoing battle between different models of man into a broader perspective, to 'inform' about what actually seems to be at stake, and to work against any scholarly 'herd behaviour.' Homer is not a bad model, but it is still not the best one. And governance by nudges bears all the problems that "new' forms of governance are known for otherwise."

Gerald Spindler deals with behavioural assumptions in legal norms, in particular in securities regulation and investor protection. The current financial crisis and in particular the fall of Lehman Brothers triggered a debate whether and to what extent the normative assumptions, on which securities legislation are based, need to be revised and adapted to the "reality," means the actual and factual behaviour of private investors in business transaction. This is particularly true with regard to the information paradigm and the rational behaviour of investors which is underpinning securities regulation and investor protection.

The paper aims to combine two different purposes: on the one hand it is meant to uncover the shortcomings of the traditional paradigms as reflected in the European legal regulatory model. On the other hand, however, the paper puts emphasis on the challenges to the legal system which result from the need to reconcile the findings of behavioural economics with existing legal regulation and to develop new guidance for legislators. The author concludes with a word of caution. The still missing coherent theory of behavioural finance and its weak normative side is said to render the task of legislators even more complicated as opposed to reliance on traditional models. He advocates "a step-by-step approach taking into account the specific behavioural deviations (which) would be likely to be more adequate than a total paternalistic approach."

Michel Faure and Hanneke Luth investigate to what extent the insights from the behavioural literature can be applied in a way to formulate concrete suggestions to policy makers. The authors show that many of the findings of the behavioural literature are very context specific and hence apply only with respect to particular products or services and particular consumer groups. Formulating general policy conclusions is therefore difficult.

However, as far as the specific domain of standard form contracts is concerned, the authors argue that the behavioural literature has shown that the traditional remedy (mostly resulting from information economics), i.e., focusing on information disclosure, will not be able to remedy market failures resulting from failing information and the "signing-withoutreading-problem." Hence, more substantive forms of intervention in standard form contracts (e.g., resulting from collective bargaining) may be indicated as a remedy. They conclude by saying that: "While we caution against overgeneralizing results from behavioural studies, in our view behavioural insights can and should be used to draft effective and efficient behaviourally informed consumer policy." The intriguing consequence of the article is that pre-market control mechanisms so heavily debated in the $1970 \mathrm{~s}$ are back on the political agenda, if legislators are ready to take the findings of behavioural economics seriously.

Willem van Boom focuses on the normative role which is granted to price transparency as a basic element of competition and contrasts it with the legislative attempts to fight price intransparency. Hence, obfuscating prices can be detrimental to consumers. Therefore, he suggests that it should be vital for policymakers to know how transparent pricing functions 
in reality. Suppliers may disclose and frame pricing information in such a way so as to influence consumers. For some suppliers, advantages may be gained by obfuscating pricethrough practices ranging from the outright hiding of price terms in the small print to subtle ways of throwing in gifts or adding charges during the vending process. Do consumers appreciate the implications of the fact that by framing price in different ways, suppliers actually try to influence their demand for products? And how does the law, broadly speaking, respond to problems of price intransparency?

In this article, Van Boom combines behavioural science insights with a legal analysis of European consumer law in order to chart some of the detrimental influences of price intransparency on the consumer decision-making process and to answer whether and to what extent European consumer law addresses these issues. In doing so, he reviews research from consumer psychology, marketing and behavioural law, and economics regarding the influence of presentation, framing, and transparency of price on the consumer decision-making process. Subsequently, it describes and evaluates the legal framework offered by European consumer law and how this framework responds to practices of price intransparency. Particular problematic pricing techniques are identified and discussed. He concludes by criticizing the full harmonization policy of the European Commission: (Transparency) must be meaningful transparency. "If indeed the full harmonization character of the UCP Directive does not allow the development of such rules on 'meaningful price transparency,' then perhaps the UCP Directive stifles rather than fosters innovation in the context of consumer empowerment."

Jan Trzaskowski starts from the premise that behavioural economics and neuroscience provide better knowledge of how the average consumer is influenced by information and commercial conduct, how consumers make decisions and he provides arguments for whether a particular commercial practice should be considered unfair. However, he states that neither approach is open to the normative aspects concerning the question of whether consumers' economic behaviour is distorted which is why they cannot differentiate between the legitimate influence of commercial activities and illegal distortion of average consumer behaviour.

The legal background to his hypothesis is the Unfair Commercial Practices Directive which is built upon the information paradigm and operates with a distinction between misleading and aggressive commercial practices. Both kinds of commercial practices are defined relatively to the perceptions of an average consumer, meaning, according to the European Court of Justice, a reasonably well-informed, reasonably observant, and circumspect consumer as well as one who is able to assess the value of the information. The author contrasts the dominating normative design with the bits and pieces in the directive and the case law of the ECJ that highlights the factual evidence needed. In "Gut Springenheide," the Court held that the national courts are entitled to take the actual behaviour of real people into account and to order testament from expert opinion or a consumer research poll for the purpose of clarifying whether a promotional statement is misleading or not. The author concludes that human cognitive architecture is limited and divided into procedural and substantial limits, which affect particular choices directly. He sums up that there is a wide gap between the real average consumer and the homo economicus that the European Court of Justice has applied in its decisions.

The final paper in this special issue on behaviour economics, consumer policy, and consumer law is a note which emphasizes the practical side of behaviour economics and consumer policy. The note addresses the OECD Consumer Policy Toolkit which was published in July 2010 (OECD 2010). The objective of the toolkit is to provide a practical handbook that policy makers can use to improve their response to consumer problems. The 
toolkit has already been applied by a document on consumer policy for government officials in Australia (Australian Government 2011). In addition, the OECD applies the toolkit in a currently ongoing assessment of consumer problems in areas such as innovation in green growth or communication markets.

Maria Lissowska, who was involved in the preparation of the toolkit, investigates in particular this toolkit which encompasses methods of detecting market malfunctioning and the tools aimed at counteracting them. The author gives a brief overview of the content of the toolkit including: changes in consumer markets in recent years and impacts of these changes on consumers such as wider opportunities of choice, but also more complex decisions and higher risks, especially on vulnerable consumers (1); introduction in different economic approaches underpinning contemporary consumer policy, in particular issues related to asymmetric information and behavioural economics (2); market failures such as information issues, regulatory, market failures, and consumer behaviour (3); stock taking of several experiences of OECD countries in screening and analysing consumer markets in order to detect problems and she describes consumer policy tools applied in OECD countries (4); sources used by OECD countries to discover causes for the malfunction of consumer markets (5); and presentation of a step-by-step process for policymakers to indicate problems in consumer markets and to decide whether to intervene in a market (6). Maria Lissowska draws the conclusion that policymakers from OECD countries need more convincing research on the impact of consumer policy tools on actual consumer behaviour.

We hope that our readers enjoy reading this intellectually stimulating material as much as we did while preparing the special issue.

\section{References}

Ariely, D. (2008). Predictably irrational: The hidden forces that shape our decisions. New York: Harper Collins.

Australian Government (2011). Consumer Policy in Australian. A companion to the OECD consumer toolkit. Available at: http://www.consumerlaw.gov.au/content/consumer_policy/downloads/Companion_ to_OECD_Toolkit.pdf.

Camerer, C. (2003). Behavioral game theory: Experiments in strategic interaction. Princeton, NJ: Princeton University Press.

Costa-Gomes, M., Crawford, V. P., \& Broseta, B. (2001). Cognition and behavior in normal-form games: An experimental study. Econometrica, 69(5), 1193-1235.

European Union. (2011). Consumer Conditions Scoreboard - Consumers at home in the single market-SEC (2011) 299. Luxembourg: Office for Official Publications of the European Union, March 2011 (ISBN 978-92-79-17862-7).

Jacowitz, J. E., \& Kahneman, D. (1995). Measures of anchoring in estimation tasks. Personality and Social Psychology Bulletin, 21, 1161-1167.

Loewenstein, G. (2004). Out of control: Visceral influences on behavior. In C. F. Camerer, G. Loewenstein, \& M. Rabin (Eds.), Advances in behavioral economics (pp. 689-723). Princeton: Princeton University Press.

Nourse, V., \& Shaffer, G. (2009). Varieties of new legal realism: Can a new world order prompt a new legal theory. Cornell Law Review, 95, 61-137.

OECD (2010). Consumer policy toolkit. Paris: Organisation for Economic Co-operation and Development.

Sobel, J. (2006). Interdependent preferences and reciprocity. Journal of Economic Literature, 43, 392-436.

Thaler, R. H., \& Sunstein, C. R. (2008). Nudge: Improving decisions about health, wealth, and happiness. New Haven: Yale University Press. 